\title{
Consentimiento informado y responsabilidad patrimonial de la Administración
}

\author{
M aría Jesús Gallardo Castillo \\ Profesora Titular de Derecho Administrativo \\ Universidad de Jaén
}

\begin{abstract}
Resumen: El consentimiento informado es un derecho básico del paciente pero también uno de los deberes que incumbe al facultativo y que determina el grado de cumplimiento de las normas y técnicas aplicables a caso. Por ello juega el importantísimo papel de servir de módulo para la valoración del funcionamiento normal o anormal del servicio, lo que determina que el mero incumplimiento de este deber de información suponga una infracción de los deberes del facultativo capaz de desplazar la carga de la prueba acerca de la relación de causalidad entre la acción médica y el daño producido así como la determinación de quién asume los riesgos padecidos, si el médico o el paciente. Sin embargo, el incumplimiento de este deber no es suficiente para que nazca el derecho a la indemnización pues para ello se requiere la producción del daño efectivo. Y a la inversa: formalizado el consentimiento éste no exonera de responsabilidad al facultativo en caso de que se produzca el acaecimiento de un riesgo no previsto en él o fruto de la imprudencia médica. Por eso el propósito de este trabajo es analizar los requisitos para un válido consentimiento, la distinta intensidad del mismo según los distintos tipos de Medicina empleados así como el resarcimiento exigible por incumplimiento de este deber y las condiciones de su ejercicio.
\end{abstract}

Palabras clave: Consentimiento informado; responsabilidad por actos médicos; riesgos; M edicina necesaria y Medicina satisfactiva.

ABST RACT: Informed consent is a basic right of the patient but also lies as a significant obligation incumbent upon doctors. This informed consent may determine to which extend norms and other applicable medical standards and technique have ben observed. Informed consent, thus, plays crucial role in the assessment of the legal correctnes of the medical staff behaviour. In that sense inobservance of that information duty might displace 
the burden of proof and also the determination of who assumes the potencial risks, either the doctor or the patient, althong it is true that in addation to the failure of this medical duty, the ocurrence of real damage must be requered. Neverthiless, formalizel conset does not either exoerate doctors in cases of medical ngligence. The aim of this papers is to analyze the requeriments for patients' consent to be valid, according to its different types and corresponding requisites.

Key Word: informed consent; responsibility by medical acts; Risks; Necessary medicine and voluntary medicine.

SUMARIO: I. CONSIDERACIONES GENERALES. II. LA ADECUADA INFORMACIÓN Y EL VÁLIDO CONSENTIMIENTO. II.1. EI sujeto activo de la información: el facultativo. II.2. El sujeto pasivo de la información: El paciente. II.3. Requisitos materiales. II.4. Requisitos de contenido. II.5. Requisitos de tiempo. III. LA CARGA DE LA PRUEBA DEL CONSENTIMIENTO. IV. LA EXIGENCIA DEL DEBER DE INFORMACIÓN Y SUS DISTINTOS GRADOS: EL CONSENTIMIENTO INFORMADO EN LA MEDICINA CURATIVA O ASISTENCIAL, EN LA MEDICINA VOLUNTARIA O NO NECESARIA Y EN LA MEDICINA ESTÉTICA. V. LA PRODUCCIÓN DE RIESGOS NO INFORMADOS Y SU IMPUTACIÓN.

\section{Consideraciones G enerales}

El derecho a la asistencia sanitaria no se agota en la prestación de atenciones médicas y farmacéuticas, sino que incluye el derecho esencial a la información previa al sometimiento a cualquier intervención quirúrgica de forma clara y comprensible para el enfermo, con la advertencia de los riesgos, señalando los posibles tratamientos alternativos y, en todo caso, solicitando el preceptivo consentimiento previo a la intervención.

Por ello, el consentimiento informado, núcleo básico del derecho de autodeterminación del paciente y parte esencial de lo que se conoce como el derecho a la autonomía personal en el ámbito de la salud, tiene una doble faz: de una parte, es un derecho básico del paciente, considerado éste como un agente moral autónomo que tiene la facultad de decidir sobre la incidencia que en su propia salud pueda tener la actividad curativa que la Medicina ejerce sobre él, lo que incluye el poder de decisión acerca de recibir o no tratamiento médico, asumir o no los riesgos inherentes a una intervención, per- 
manecer enfermo o sanar, o incluso a perder la vida ${ }^{1}$. $Y$ de otra, integra uno de los contenidos definidores de la lex artis en tanto que constituye uno de los deberes que incumbe al facultativo y calibra el grado de cumplimiento de las normas y técnicas aplicables a caso. Desde este punto de vista, el consentimiento informado puede concebirse como un acto médico más ${ }^{2} 0$, si se quiere, como parte de toda actuación asistencial ${ }^{3}$, constituyendo, en todo caso, una exigencia ética y legalmente exigible a los miembros de la profesión médica. En este sentido, la SAP de Madrid de 19 de diciembre de $2007^{4}$ establecía el siguiente silogismo: "Si el médico tiene la obligación de informar al paciente, como consecuencia de una exigencia ética y legal, y el consentimiento informado de éste es presupuesto de toda actuación asistencial parece una consecuencia lógica que pase a constituir elemento esencial de la lex artis".

Desde su configuración como exigencia derivada del derecho de autodeterminación del paciente, el consentimiento informado constituye un derecho humano fundamental, fruto de las últimas aportaciones realizadas en la teoría de los derechos humanos y derivación necesaria de los clásicos derechos a la vida, a la integridad física y a la libertad de conciencia, así como del Derecho a la libertad personal, a decidir por sí mismo en lo atinente a la propia persona y a la propia vida y consecuencia de la autodisposición sobre el propio cuerpo, regulado primeramente por la Ley 14/ 1986, de 25 de abril, General de Sanidad ${ }^{5}$ (en adelante, LGS) y reconocido después en el Convenio

1 PELAYO GONZÁLEZ-TORRE, A. La intervención jurídica de la actividad médica: El consentimiento informado. Madrid, Dykinson, 1997, págs. 81 y 82.

2 REQUERO IBÁÑEZ, J.L. "EI consentimiento informado y la responsabilidad patrimonial de las Administraciones", en la obra colectiva La responsabilidad patrimonial de la Administración sanitaria. Cuadernos de Derecho Judicial. Consejo General del Poder Judicial, 2002, pág. 324.

${ }^{3}$ Así lo califican las SSTS 29 de mayo (RJ 2003|3916), de 23 de julio de 2003 (RJ 2003|5462) y de 21 de diciembre 2005 (RJ 2005(10149). En la doctrina, GALÁN CORTES, J.C. "Consentimiento informado: situación actual e incidencia en las especialidades médicas", Actualidad del Derecho Sanitario, no 91, 2003, págs. 119 a 124.

4 JUR 2008|81466; Recurso 79/ 2007.

${ }^{5}$ El art. 10.6 LGS exigía "el previo consentimiento escrito del usuario para la realización de cualquier intervención", lo que presuponía que con anterioridad se le hubiera suministrado al paciente "información completa y continuada, verbal y escrita, sobre su proceso, incluyendo diagnóstico, pronóstico y alternativas de tratamiento" (apartado 5)". Sobre este precepto debe consultarse MARÍN GAMEZ, J.A. "A vueltas con la constitucionalidad del art. 10.6 de la Ley General de Sanidad: la relevancia jurídica del consentimiento reformado", en Revista General de Derecho, núms. 610-611, julio-agosto 1995, págs. 8237 a 8257. 
Internacional para la Protección de los Derechos Humanos y la Dignidad del Ser H umano con respecto a las Aplicaciones de la Biología y de la Medicina, pasando a ser Derecho interno español y, por ende, formando parte de toda actuación sanitaria 6 . Con esta regulación y obviando precedentes más polémicos, como así afirma la STSJ Cantabria de 12 de enero de 20077, el derecho de autonomía del paciente, como vertiente del respeto a la dignidad humana, cobraba carta de naturaleza legal en nuestro ordenamiento. Y dentro de éste, el consentimiento informado ha venido a propiciar el cambio de mentalidad en el ámbito sanitario, de manera que las relaciones médicas pasan a ser horizontales y no meramente verticales o regidas por el aire de paternalismo de antaño. Sin embargo, las estrictas exigencias de la anterior normativa al abordar lo que en nuestro país se concebía como un instituto en cierta forma revolucionario, una vez se ha adquirido experiencia al respecto y ha madurado la evolución de la relación médico-paciente, se han visto matizadas en la actual regulación. Concretamente, la Ley 41/2002, de 14 de noviembre, básica reguladora de la autonomía del paciente y de derechos y obligaciones en materia de información y documentación clínica ${ }^{8}$, obedece a dos hitos esenciales,

\footnotetext{
${ }^{6}$ Tal y como afirma la STS de 11 de mayo de 2001 (RJ 2001/6197; Recurso 1044/ 1996), desde esta perspectiva, el consentimiento informado encuentra fundamento y apoyo, de un lado, en la misma Constitución Española, y, más en concreto, en la exaltación de la dignidad de la persona ( art. 10.1) y en la libertad (arts. 1.1 y 9.2) de donde se deriva la autonomía del individuo para elegir entre las diversas opciones vitales que se presenten de acuerdo con sus propios intereses y preferencias -STC 132/ 1989, de 18 de junio- y, y de otro, en los Pactos Internacionales como la Declaración Universal de Derechos H umanos de 10 de diciembre de 1948 proclamada por la Asamblea General de las Naciones U nidas ( principalmente en su Preámbulo y arts. 12, 18 a 20, 25, 28 y 29), el Convenio para la Protección de los Derechos H umanos y de las Libertades Fundamentales, de Roma de 4 de noviembre de 1950 ( arts. 3, 4, 5, 8 y 9) y el Pacto Internacional de Derechos Civiles y Políticos de Nueva York de 16 de diciembre de 1966 (arts. 1, 3, 5, 8, 9 y 10). Por último, el art. 3 de la Carta 2000/ CE 364/ 01, de los Derechos Fundamentales de la Unión Europea prescribe como parte innata a la integridad de la persona: "1.- Toda persona tiene derecho a su integridad física y psíquica. 2.- En el marco de la medicina y la biología se respetarán en particular: el consentimiento libe e informado de la persona de que se trate, de acuerdo con las modalidades establecidas en la ley...". En igual sentido, las STS de 12 de enero de 2001. RJ 2001|3; Recurso $3688 / 1995$.
}

${ }^{7}$ JUR 2007\122409

${ }^{8}$ La Ley 41/ 2002, de 14 noviembre establece en su art. 2 los principios básicos de dignidad de la persona humana, derecho a decidir libremente y respeto a la autonomía de su voluntad, al afirmar con absoluta rotundidad que "toda actuación en el ámbito de la sanidad requiere, con carácter general, el previo consentimiento de los pacientes o usuarios" y añade que el consentimiento... "debe obtenerse después de que el paciente reciba una información adecuada" y "se ha- 
como indica en su propio preámbulo: el Convenio del Consejo de Europa para la protección de los derechos humanos y la dignidad del ser humano respecto de las aplicaciones de la biología y la medicina (Convenio conocido como de O viedo), suscrito el día 4 de abril de 1997 y en vigor para España desde el 1 de enero de 2000, y el Seminario conjunto entre el Consejo General del Poder Judicial y el Ministerio de Sanidad y Consumo, sobre información y documentación clínica, entre cuyos resultados se encuentra la constitución de un grupo de expertos a quienes se encargó la elaboración de unas directrices para el desarrollo futuro de este tema, suscribiendo un dictamen el 26 de noviembre de 1997, que, como indica la propia norma, ha sido tenido en cuenta en la elaboración de los principios fundamentales de esta Ley. Por su parte, la elaboración casi paralela de la legislación autonómica ha propiciado que entre ambas no exista total coincidencia en determinados aspectos. Conflicto de normas que ha de resolverse dando primacía a la legislación básica sobre la de desarrollo.

Esta concepción del consentimiento informado como consecuencia inherente a la autonomía personal trae, como primera exigencia, que la persona pueda tomar conciencia, en lo posible y mientras lo desee, de la situación de salud en que se halla, de las posibilidades para afrontar la enfermedad, de los riegos que corre, que no se le sustituya sin justificación en el acto de tomar las decisiones que le corresponden y que se le permita adoptar medidas de prevención que le sea posible.

Pero sin duda, la verdadera concreción del consentimiento informado no se produjo hasta su concepción como parte integrante de la lex artis. Sólo desd entonces, el consentimiento informado empezó a jugar el importantísimo papel de servir de módulo para la valoración del funcionamiento normal o anormal del servicio ${ }^{9} 0$, si se quiere, de criterio valorativo de la corrección del con-

rá por escrito en los supuestos previstos en la Ley". En su art. 3 esta norma define el consentimiento informado como "la conformidad libre, voluntaria y consciente de un paciente, manifestada en el pleno uso de sus facultades después de recibir la información adecuada, para que tenga lugar una actuación que afecta a su salud" y el art. 4 establece que la información, como regla general, "se proporcionará verbalmente dejando constancia en la historia clínica, comprende, como mínimo, la finalidad y la naturaleza de cada intervención, sus riesgos y sus consecuencias". La información clínica forma parte de todas las actuaciones asistenciales y "será verdadera, se comunicará al paciente de forma comprensible y adecuada a sus necesidades y le ayudará a tomar decisiones de acuerdo con su propia y libre voluntad".

${ }^{9}$ Así las SSTS de 2 de octubre (RJ 1997\7405) y 16 de diciembre de 1997 (RJ 1997/8690). 
creto acto médico ejecutado según las técnicas habituales contrastadas, las especiales características de su autor y los factores influyentes en el paciente, lo que determina que el mero incumplimiento de este deber de información ${ }^{10}$ suponga ipso facto una infracción de la lex artis ${ }^{11}$ capaz de condicionar el desplazamiento de la carga de la prueba acerca de la relación de causalidad entre la acción médica y el daño producido así como la determinación de quién asume los riesgos padecidos, si el médico o el paciente. En consecuencia, la omisión del deber de informar revela per se la anormalidad del servicio, causa necesaria, aunque, como veremos, no suficiente, para que nazca el derecho a la indemnización ${ }^{12}$.

Efectivamente. Si bien en línea de principios, el título de imputación para que entre en juego el instituto resarcitorio es tanto el funcionamiento normal como el anormal del servicio sanitario, sin embargo, cuando la causa de la pretensión indemnizatoria descansa en la omisión del deber de información, la anormalidad del servicio se revela como el único camino viable que puede conducir al éxito de la misma. Y aunque la falta de información constituye una anormalidad en sentido estricto, sin embargo, se requiere un desva-

\footnotetext{
${ }^{10}$ Así la STS de 25 de abril de 1994 (RJ 1994|3073) señala como uno de los deberes inexcusables del médico el de "informar al paciente 0 , en su caso, a los familiares del mismo, siempre, claro está, que ello resulte posible, del diagnóstico de la enfermedad o lesión que padece, del pronóstico que de su tratamiento puede normalmente esperarse, de los riesgos que el mismo, especialmente si este es quirúrgico, pueden derivarse y, finalmente, y en el caso de que los medios de que se disponga en el lugar donde se aplica el tratamiento puedan resultar insuficientes, debe hacerse constar tal circunstancia, de manera que, si resultase posible, opte el paciente o sus familiares por el tratamiento del mismo en otro centro médico más adecuado".
}

11 Las SSTS de 26 de de noviembre de 2004 (RJ 2005|22; Recurso 280/ 2001), de 26 de enero de 2006 (RJ 200614346; Recurso 5681/ 2001), de 12 de diciembre de 2006 RJ 200619563; Recurso 4317/ 2002), de 16 de enero de 2007 (RJ 2007/1220; Recurso 5060/ 2002) y de 23 de febrero de 2007 (RJ 2007/884; Recurso 3551/ 2002) afirman que "el defecto de consentimiento informado se considera como incumplimiento de la lex artis ad hoc y revela un funcionamiento anormal del servicio sanitario".

12 Indica la STS de 26 de febrero de 2004 (RJ 2004|3889; Recurso 8656/ 1999) que "aun cuando la falta de consentimiento informado constituye una mala praxis ad hoc, no es lo menos que tal mala praxis no puede per se dar lugar a responsabilidad patrimonial si del acto médico no se deriva daño alguno para el recurrente y así lo precisa la sentencia de 26 de marzo de 2002 (RJ 200213956), que resuelve recurso de casación para unificación de doctrina (Recurso 890/2001) en la que afirma que para que exista responsabilidad es imprescindible que el acto médico se deriva un daño antijurídico porque si no se produce éste la falta de consentimiento informado no genera responsabilidad". 
Ior en el resultado. Dicho a la inversa: si se ha omitido el deber de información pero el servicio ha funcionado correctamente no hay nada que resarcir: la falta de consentimiento informado habrá podido constituir una actuación reprochable del facultativo pero carente de entidad suficiente como para dar lugar al nacimiento de la responsabilidad patrimonial.

En definitiva, la falta de información no constituye por sí misma causa de resarcimiento pecuniario, que sólo procederá si, y sólo si, junto a aquélla concurre un daño derivado y del cual no se obtuvo la información adecuada. El daño pues, no es, en sí mismo la falta de información y el no otorgamiento del consentimiento del paciente, sino la pérdida de su poder de autodeterminación personal. Luego volveremos con mayor detalle a esta cuestión.

De acuerdo con lo razonado hasta ahora, el consentimiento informado puede definirse como el derecho de todo paciente a obtener la información suficiente, clara, completa, veraz y adecuada acerca del padecimiento que sufre, de su diagnóstico, pronóstico y posibles tratamientos, riesgos y alternativas, a fin de que pueda emitir su conformidad libre, consciente y voluntaria de recibirlos, asumirlos y, en fin, de valorar, ponderar y decidir el coste-beneficio de unos y otros.

Alguna sentencia ha ofrecido también alguna definición de consentimiento informado, y así la STSJ de Galicia de 24 de diciembre de $2003^{13}$ lo define como "la conformidad expresa del paciente, manifestada por escrito, previa obtención de la información adecuada para la realización de un procedimiento diagnóstico o terapéutico que afecte a su persona y que comporte riesgos importantes, notorios o considerables", por lo que, así configurado, ha de considerar que el consentimiento informado tiene una naturaleza jurídica dual de derecho-deber: el primero para el paciente, el segundo para el médico que queda obligado a obtenerlo.

La definición legal nos la ofrece el art. 3 de la citada Ley 41/ 2002, de 14 de noviembre que lo define como "la conformidad libre, voluntaria y consciente de un paciente, manifestada en el pleno uso de sus facultades después de recibir la información adecuada, para que tenga lugar una actuación que afecta a su salud". La Ley consagra el derecho a la información clínica y asis-

13 JUR 2004|65026; Recurso 478/ 2001. 
tencial. La primera la conceptúa como "todo dato, cualquiera que sea su forma, clase o tipo, que permite adquirir o ampliar conocimientos sobre el estado físico y la salud de la persona, o la forma de preservarla, cuidarla, mejorarla o recuperarla" ( art. 3), y la segunda, la que deriva de la relación continuada y permanente entre médico y paciente, en tanto que reconoce el derecho a conocer toda la información dispone sobre cualquier actuación que se realice en el ámbito de su salud (art. 4.1).

Esta definición legal es válida para fijar de modo preciso extremos tan importantes como su ámbito, quien tiene que dar esa información, a quién, su extensión, excepciones y límites. Y es que para que la información ofrecida por el facultativo responsable de emitirla y el consentimiento del paciente tras recibirla sean capaces de cumplir su finalidad es preciso que aquélla cumpla con unos requisitos de contenido, forma y tiempo determinados y que éste se preste con conocimiento de causa y en unas condiciones adecuadas. Para ello es preciso que se comuniquen convenientemente las características de la intervención quirúrgica o del tratamiento que ha de recibirse, los riegos que uno u otro conllevan, las alternativas y las complicaciones que podrían producirse en ese momento o a posteriori, y hacerlo con un contenido completo, de una forma inteligible y, en la medida de lo posible, con antelación suficiente. En definitiva, en este tema importa no sólo el qué, sino muy especialmente el cómo.

\section{LA ADECUADA INFORMACIÓN Y EL VÁLIDO CONSENTI- MIENTO}

\section{II.1. El sujeto activo de la información: el facultativo}

La Jurisprudencia no trata de forma directa esta cuestión sino que lo hace en su relación con la carga de la prueba. Como es bien sabido -y después se volverá nuevamente sobre la cuestión-, el consentimiento informado y, más en concreto, la información previa a él, sin dejar de configurarse como un derecho del paciente, es también en buena medida un instrumento que permite exonerar de responsabilidad al Centro médico y, en su caso, al facultativo o facultativos intervinientes en el proceso médico. Es por esta razón que el sujeto que deba emitirla y que ha de hacerlo convenientemente es, en principio y con las matizaciones que inmediatamente se dirán, justamente aquél o aquéllos sobre los que se sienta después la presunción de asunción del riesgo en caso de desinformación (de "consentimiento desinformado", dice la Jurisprudencia). Ahora bien, la mayoría de las resoluciones judiciales no individuali- 
zan en un médico concreto y ni siquiera en el equipo esta obligación de información, sino que la dirige al Centro hospitalario (STS de 16 de octubre de 199814) o incluso al Servicio Nacional de la Salud (STS de 7 de marzo de 200015) y en ocasiones la hace recaer en ambos, al Centro y al médico que figura como responsable de la operación (STS de 19 de junio de $2007^{16}$ ). Algo más concretas fueron las SSTS de 28 de de diciembre de $1998^{17}$ y de 19 de abril de $1999^{18}$ que hacen recaer este deber sobre "el profesional de la Medicina (no dice cuál), por ser quien se halla en situación para conseguir su prueba".

La meritada Ley 41/ 2002, en su art. 4.3 distribuye este deber en dos niveles: de una parte, el garante de la información y de otra, los demás responsables. El primero es "el médico responsable del paciente", que es quién ha de garantizar "el cumplimiento de su derecho a la información". Médico responsable que es, en definitiva, y como afirma la STS de 15 de mayo de $2008^{19}$ el profesional que tiene a su cargo la coordinación de la información y la asistencia sanitaria del paciente o del usuario con el carácter de interlocutor principal del mismo en todo lo referente a su atención e información, pero que no tiene que coincidir con quienes intervengan en todo el curso causal. Los segundos lo son "Ios profesionales que le atiendan durante el proceso asistencial o le apliquen una técnica o un procedimiento concreto".

El precepto, sin embargo, adolece de cierta imprecisión puesto que la garantía de la totalidad de la información en un proceso médico más o menoslargo o más o menos complejo, en el que han de desarrollarse multitud de pruebas médicas con capacidad de incidencia negativa en el paciente, y en el que intervienen distintos profesionales según su correspondiente ámbito de intervención, no puede, no debe, hacerse recaer en un solo interlocutor, entre otras razones, porque la lógica falta de especialización de todas las áreas im-

\footnotetext{
${ }^{14}$ RJ $1998 \backslash 7565$.

15 RJ $2000 \backslash 1508$.

${ }^{16}$ RJ 2007\5572; Recurso 2047/ 2000.

17 RJ 1998\10155.

${ }^{18}$ RJ $1999 \mid 2588$.

${ }^{19}$ RJ 2008|3078; Recurso 279/ 2001.
} 
piden hacerlo con pleno conocimiento de causa y con los requisitos de contenido y forma que luego de analizarán. Como bien afirma Galán Cortés ${ }^{20}$, el médico responsable podrá y deberá propiciar o fomentar tal información, pero no garantizarla, siendo los especialistas de cada actuación concreta quienes sí deben velar por que la misma se facilite al paciente en los términos precisos.

Luego entonces, y dada la ulterior repercusión que este deber de garante tiene respecto a la responsabilidad frente al juez y frente a una eventual acción de regreso de la Administración, debe diferenciarse cuándo el médico actúa como mero interlocutor o portavoz ${ }^{21}$, si acaso principal, entre el Centro hospitalario y el paciente y ante el juez, y cuándo éste cumple además esa función de garante y de directo responsable de la información que establece el art. 4.3.

Pues bien, haciendo un esfuerzo de síntesis, y a la vista de las sentencias que han tenido oportunidad de pronunciar nuestros Tribunales, pueden dejarse sentadas las siguientes reglas generales:

En primer lugar, la mencionada STS de 15 de mayo de 2008 afirma que cuando el informe radica en la actuación de la entidad sanitaria resulta suficiente "un solo informador" ya que establecer más exigencias llevaría al absurdo, pues no cabe esperar que, a la vista de cada intervención quirúrgica que se avecina, procedan cada uno de los llamados a intervenir, tanto en ella como en sus pruebas previas y posteriores, como son el ginecólogo, el cirujano, el anestesista o el analista, a redactar bajo su propia e individual iniciativa una información escrita de los riesgos que a su personal juicio le conciernen, sino que, al contrario, lo procedente y ajustado a las invocadas circunstancias es que tales informaciones sean conjuntamente ofrecidas por la "entidad sanitaria responsable de la prestación" con arreglo a criterios uniformes, generalmente aceptados y conformes con el dictado legal.

En segundo lugar, tratándose de intervenciones quirúrgicas no se establece taxativamente la obligación de que la información deba ser facilitada

${ }^{20}$ GALÁN CORTES, J.C. Responsabilidad civil médica. Madrid, Cívitas, 2005, pág. 278.

${ }^{21}$ En este sentido, LIZARRAGA GONELLI, E. "La información y la obtención del consentimiento en la nueva Ley 41/2002, básica reguladora de la autonomía del paciente y de derechos y obligaciones en materia de información y documentación clínica", en la obra colectiva dirigida por GONZÁLEZ SALINAS, P. y LIZARRAGA BONELLI, E. Autonomía del paciente, información ehistoria clínica (Estudios sobre la Ley 41/2002, de 14 de noviembre), Madrid, Ed. Cívitas, 2004, pág. 265. 
por el médico que haya de practicarla, pudiendo hacerlo "cualquier facultativo", con tal, obviamente, de que esté en condiciones de facilitar la información en las condiciones y con los requisitos de veracidad, completud y adecuación que después se dirán (STS) de Valencia de 24 de diciembre de $2003^{22}$.

En tercer lugar, según la misma sentencia, no puede delegarse en una enfermera, tal y como aconteció en el supuesto fáctico en ella contemplado en donde firmaba como única responsable.

Por último, cabe rechazar de plano, como así lo hizo la SAP de Valencia de 27 de febrero de $2006^{23}$, el consentimiento informado sometido a su consideración por tratarse de un documento impreso, en el que únicamente aparece el nombre del paciente, con zonas de puntos que aparecen en blanco, "sin referencia alguna del médico responsable, del Centro al que pertenece 0 en el que realiza su labor médica, y simplemente con una firma en su parte posterior". Lo curioso en este caso es que la Sala reconoce expresamente que la existencia del consentimiento y de una información previa veraz, clara, y suficiente se había acreditado por otros medios de suficiente convicción pero, pese a ello, considera desacertado este modo de proceder por no ser una buena práctica en pro de acreditar la voluntad de las partes.

\section{II.2. El sujeto pasivo de la información: El paciente}

El titular del derecho a recibir información y de emitir o no su consentimiento no puede ser otro que el usuario del servicio sanitario, obviamente cuando éste es mayor de edad y está en pleno uso de sus facultades para comprender y tomar las decisiones que tenga por conveniente.

En este sentido, resulta oportuno destacar que el art. 5 de la Ley 41/ 2002 viene a establecer tres niveles diferenciados según las aptitudes y capacidades del paciente:

a) En condiciones de normalidad, es decir, si el paciente posee las aptitudes necesarias para entender y emitir su voluntad, la información

\footnotetext{
22 JUR 2004|65026; Recurso 478/ 2001.

${ }^{23}$ AC 20061968; Recurso 449/ 2005.
} 
deberá ser recibida por él, por ser "el titular del derecho a la información". En este caso no será preceptiva la información a terceras personas (familiares o allegados), pero podrán serlo siempre que "el paciente lo permita de manera expresa o tácita" ( art. 5.1).

b) En caso de incapacidad, el paciente continúa siendo el titular de la información, pero habrá de facilitársela "de modo adecuado a sus posibilidades de comprensión". En este caso la obligación de informar se extiende también a "su representante" (art. 5.2).

c) Sólo si el paciente carece de capacidad para entender la información a causa de su estado podrá prescindirse de facilitársela, en cuyo caso serán las personas vinculadas a él por razones familiares o de hecho quienes reciban la información (art. 5.3). Aún en este caso el paciente participará, en la medida de lo posible, en la toma de decisiones a lo largo del proceso sanitario (art. 9.5 in fine).

El precepto parece tan sólo aludir a situaciones de incapacidad de carácter originario y natural. Sin embargo, entiendo que ello puede extenderse a aquéllas otras en que se alcanza ese nivel de inconsciencia, de incapacidad transitoria o de imposibilidad de comprender por razones de anestesia, de ansiedad o de nerviosismo que incapacita a la persona para entender la información y para emitir un consentimiento de un modo válido, eficaz y responsable. Así lo vino a entender a STS de e 29 de julio de $2008^{24}$ que enjuiciaba la validez de un consentimiento dado por un paciente ansioso, sedado y con anestesia epidural, estando ya en quirófano y justamente en el momento previo a ser intervenido quirúrgicamente. Como no puede ser de otro modo, la sentencia afirma que en estas condiciones no pueden entenderse cumplidos los requisitos exigidos para tener por emitido y por válido el consentimiento del paciente, puesto que, en todo caso, en las circunstancias en que se da por prestado, el consentimiento o no existió (alguien inconsciente no puede consentir nada) o fue nulo al concurrir un vicio en la voluntad de tal calibre que invalidaría su prestación ${ }^{25}$.

\footnotetext{
24 RJ 2008|4638; Recurso 541/ 2002.
}

25 La sentencia afirma textualmente: "Un paciente que se encuentra ansioso, estirado en una mesa de operaciones y sedado, nunca puede ser poseedor de todas sus facultades cognitivas y cognoscitivas. Por ello, en todo caso, se debe considerar que si hubo prestación de consentimiento, el paciente incurrió en error, al existir un falso e inexacto conocimiento de la realidad, ya que no estaba en condiciones hábiles para que fuera consciente, como mínimo del objeto de la intervención y de sus consecuencias". 
Ahora bien, esta asimilación entre las condiciones que afectan a la capacidad cognitiva del paciente ya sean tanto originarias como derivadas no puede realizarse en términos absolutos, puesto que en el primer caso, que es el que prevé el art. 5, el derecho de información pasa a ser ejercitado por terceros vinculados al paciente por razones familiares o de hecho que lo harán en su nombre. Pero no así en este segundo caso en que no cabe sustituir la voluntad personal, individual e intransferible del paciente "a decidir por sí mismo lo atinente a la propia persona y a la propia vida, y en consecuencia a la autodisposición del propio cuerpo" -en palabras de la STS 11 de mayo de 200126- por la de ninguna otra persona, por muy íntima y allegada que ésta sea, al menos si no concurren -como luego veremos- circunstancias adicionales, no tanto de necesidad como de urgencia o riesgo grave, actual e inminente para su vida ${ }^{27}$.

Así pues, existen dos reglas generales: De una parte, la necesidad de obtención de consentimiento informado con carácter previo a la prestación del servicio sanitario. Y de otra, que la recepción de la información y emisión del consentimiento se haya efectuado de forma personal por parte de la persona adulta destinataria de la actuación médica.

Sin embargo, ambas reglas son susceptibles de excepcionarse, según se deriva de los arts. 9.2 y 9.3 de la Ley $41 / 2002$. Y así, la primera encuentra su excepción en las situaciones en que tratándose, de intervenciones clínicas indispensables a favor de la salud del paciente, no se precisa el consentimiento informado previo en los dos siguientes supuestos:

a) Cuando existe riesgo para la salud pública a causa de razones sanitarias establecidas por la Ley.

b) Cuando existe riesgo inmediato grave para la integridad física o psíquica del enfermo y no es posible conseguir su autorización. En este

${ }^{26}$ RJ 2001|6197; Recurso 1044/ 1996.

27 En este sentido, la STS) de Navarra de 6 de septiembre de 2002 (RJ 200218991; Recurso 9/2002) afirma que no puede excluirse el consentimiento informado, por la circunstancia de que la intervención fuera necesaria, "pues no es la necesidad de una intervención, una de las causas de excepción a ese consentimiento informado, sino la urgencia (... ), pues sólo puede prescindirse del consentimiento informado cuando la urgencia no permita demoras por poderse ocasionar lesiones irreversibles o existir peligro de fallecimiento, circunstancia esta que evidentemente no se da en el caso de autos". 
caso, cuando las circunstancias lo permitan, deberá consultarse a sus familiares o a las personas vinculadas de hecho a él.

La excepción a la segunda regla consiste en que el consentimiento no sea otorgado por el paciente sino por terceras personas que ostenta su representación, lo que acontecerá en los tres siguientes casos que establece el art. 9.3:

a) Cuando el paciente no sea capaz de tomar decisiones, a criterio del médico responsable de la asistencia, o su estado físico o psíquico no le permita hacerse cargo de su situación.

b) Cuando el paciente esté incapacitado legalmente.

c) Cuando el paciente menor de edad no sea capaz intelectual ni emocionalmente para comprender el alcance de su intervención.

En el primer caso la falta de representación legal podrá sustituirse con la prestación del consentimiento por parte de las personas vinculadas al paciente, y en los dos últimos casos, el consentimiento lo otorgará el representante legal, si bien tomando siempre en consideración la opinión del paciente si está en condiciones de darla, lo cual se presume en el caso del menor de edad si éste tiene más de doce años cumplidos. No debe olvidarse el principio general de dar participación al propio interesado a lo largo de todo el proceso sanitario (art. 9.5).

Cuestión distinta es el caso de dos limitaciones que pueden condicionar la emisión y recepción de esta información clínica: La primera viene dada por el ejercicio del derecho-deber de no emitir la información por parte del médico o hacerlo sólo en parte (art. 5.4). Es el Ilamado "privilegio terapéutico", que sólo podrá entrar en juego cuando, a criterio del médico, la información una vez recibida por el paciente es susceptible de causar unos efectos perniciosos y una repercusión extraordinariamente negativa e irreversible en la salud de aquél. Se trata de una especie de conflicto de intereses entre el bien jurídico que puede verse lesionado por la información y el derecho mismo a obtenerla. En cualquier caso, esta excepción o limitación terapéutica, que legitima al médico a silenciar toda o parte de la información clínica al paciente, debe aplicarse con suma cautela y en situaciones de un peligro real contrastado 0 , al menos, previsible, sobre la salud del paciente y no fundamentarse en un mero juicio especulativo huérfano de base o indicios racionales. Se trata, en cualquier caso, de una situación límite en la que el equilibrio, la ponderación y la ecuanimidad de los médicos han de marcar, en última instancia, la fron- 
tera entre el derecho del paciente a conocer su situación real y las posibilidades de mejora o curación y el deber del médico de velar por la salud del paciente: de un lado, para ponderar racionalmente situaciones en las que el médico ha de cumplir con el inexorable deber de informar, y de otro, para evitar, expansivamente impunidades inadmisibles, con quiebra del derecho de autodeterminación del paciente.

La otra viene dada por el derecho del paciente "a no saber". En este caso el paciente sustituye, por las razones que fueren, el ejercicio de un derecho por otro: el de obtener una información completa y veraz sobre su diagnóstico, pronóstico y alternativas por el de la renuncia a obtenerla. Ahora bien, ni este derecho es absoluto en su contenido ni incondicionado en cuanto a la forma. El propio art. 9.1 establece que "la renuncia del paciente a recibir información está limitada por el interés de la salud del propio paciente, de terceros, de la colectividad y por las exigencias terapéuticas del caso. Cuando el paciente manifieste expresamente su deseo de no ser informado, se respetará su voluntad haciendo constar su renuncia documentalmente, sin perjuicio de la obtención de su consentimiento previo para la intervención".

Como se ha venido afirmando y después se analizará con mayor profundidad, el consentimiento del paciente no puede ser considerado un mero requisito formal de asentimiento, sino un verdadero acto de voluntad en el que el paciente, consciente de la trascendencia de su manifestación e informado debidamente del acto médico al que se va a someter, consiente en ello. Así considerado, y como afirma la SAP de León de 18 de junio de $2008^{28}$, la trascendencia del acto exige que la declaración de voluntad provenga de una persona competente, con capacidad para consentir, informada de forma suficiente y comprensible, y que a partir de ahí actúe de forma voluntaria, siendo el resultado final la exteriorización del consentimiento que, además, habrá de ser actual como garantía de subsistencia.

Por ello, el primer presupuesto lógico para poder afirmar que el sujeto adopta una decisión responsable y libre es la existencia de condiciones psíquicas mínimas que aseguren la madurez de su decisión. Con ello quedarán excluidas las personas que por padecer algún tipo de anomalía o deficiencia mental estén incapacitadas para decidir y a quienes se encuentran en una situación de trastorno mental que puede estar motivado por el propio estado de

${ }^{28}$ ARP 2008|531; Recurso 5055/ 2008. 
la enfermedad. En estos casos suele reconocerse sin dificultad que para decidir en qué circunstancias estas personas conservan su capacidad de obrar habrá de atenderse al grado de incapacidad que padezcan, algo que en definitiva remite a las circunstancias del caso concreto, no requiriéndose declaración judicial de incapacidad que así lo declare para que legítimamente pueda ser sustituida su voluntad por una persona vinculada al enfermo por razones familiares o de otra índole que evidencien dicha vinculación o dependencia.

En cualquier caso, se requiere consentimiento informado (a excepción de los casos anteriormente examinados que determina el art. 9.2 de la Ley 41/ 2002) emitido por el representante legal de las personas que carezcan de la capacidad necesaria, por lo que ni siquiera una eventual valoración por parte del facultativo de la conveniencia o no de emitir la información clínica al menor o al incapacitado pueda plantearse respecto de su propio representante legal, pues a todos los efectos, ésta es la persona que le sustituye y que ostenta todo el derecho y toda la legitimación a obtener la información y a decidir, y sin que este consentimiento del representante pueda ni deba ser suplido, sin ningún control judicial, por los facultativos.

Dejando a un lado el derecho del propio menor a emitir su parecer -y luego analizaremos si a decidir por sí mismo y aún en contra de la voluntad de quienes ejercen su patria potestad-, lo que en cualquier caso no deja duda alguna es el derecho de los padres o tutores a recibir información y a emitir, en su caso, su ulterior consentimiento y el deber de los facultativos a facilitárselo, sin que en modo alguno puedan tomar una decisión sobre la salud del menor sin el concurso de esta voluntad. La STSJ de Navarra de 6 de septiembre de $2002^{29}$ constituye un buen ejemplo de ello. En este caso la menor había sido intervenida sin el consentimiento de los padres dando lugar a un desafortunado resultado. La Clínica recurrente intenta ampararse en el deber de los padres que establece el art. 110 del Código Civil de velar por los hijos menores, de donde colige que, a su juicio, la intervención quirúrgica debía efectuarse en cualquier caso, ya que constituía el procedimiento de eliminación de una grave disfunción que padecía su hija, lo que, a su entender, "enervaría los efectos de la ausencia del consentimiento informado al primar, sobre éste, el deber de los padres de velar por sus hijos que, referido al caso concreto, determinaría la exigencia de someter a la menor a la intervención quirúrgica a que se refiere el objeto de autos". El motivo alegado no era atendible, pues afirma la sentencia que:

${ }^{29}$ RJ 2002/8991; Recurso 9/ 2002. 
“ Sin entrar en disquisiciones de índole teórico o sociológico, no puede mantenerse que el cumplimiento de dicha obligación enerva la obligación que los facultativo tienen de informar debidamente a los mayores de edad o a los padres de los menores de las circunstancias y riesgos directos o indirectos que presenta una determinada intervención o sus efectos, ya que, precisamente, dicha información constituye el soporte cabal y adecuado de la obligación tanto legal como de índole moral que los padres tienen sobre la vida y salud de sus hijos, ya que el conocimiento de los riesgos que comporta una técnica médica puede determinar la posibilidad de optar por otra y, también, la de posponer su realización ante la esperanza de que en el futuro pueda realizarse aquélla mediante sistemas quirúrgicos o no que puedan eliminar o reducir los riesgos existentes.

Es cierto que puede discutirse la necesidad o no del consentimiento de los padres ante situaciones extremas y urgentes, pero no es menos cierto de que en tales supuestos también es distinta la regulación legal de la necesidad de la previa y cumplida información por los facultativos.

En definitiva, la materia no queda regulada por las normas generales que determinan una obligación de tal carácter o índole global de los padres sobre sus hijos menores, sino por las que determinan el consentimiento previo, su información y los supuestos en que puede excluirse total o parcialmente, ante determinadas situaciones extremas o de urgencia, que se examinarán cuando se trate el tema de fondo que es objeto del presente recurso, pero no ante la pretensión de infracción de la norma ahora analizada, que en modo alguno se ha producido, todo lo cual determinada la desestimación del motivo de casación ahora examinado.

Ninguna duda debe ofrecer, que el consentimiento debió ser prestado por los padres, en cuanto eran los representantes legales de la menor, por estar ésta sometida a la patria potestad de aquellos".

Cuestión distinta y, por supuesto, más espinosa es la que hace referencia a si el menor de edad puede tomar una decisión que pueda entrar en clara confrontación con la de quienes ejercen su patria potestad y, más en concreto, si puede eficazmente negarse a recibir el tratamiento y, en su caso, la intervención quirúrgica que, a juicio de los facultativos, resulta no ya sólo más conveniente a su salud sino que constituye la única solución viable para salvar 
su vida. ¿Qué debe primar en este caso: el derecho a decidir sobre su salud y su vida o el derecho a la propia vida?, ¿en el caso de los menores existe ese derecho? Entiendo que no, por dos razones legales: una porque el art. 154.3 del Código civil establece que "si los hijos tuvieren suficiente juicio deberán ser oídos siempre antes de adoptar decisiones que les afecten" por lo que, entiendo que el derecho a ser oídos no debe ampliarse más allá de sus propios términos hasta el extremo de otorgar un poder de decisión en ámbitos cuya legitimidad es más que dudosa. Y dos, porque el art. 158.3 del mismo cuerpo legal establece que "el Juez, de oficio o a instancia del propio hijo, de cualquier pariente o del Ministerio Fiscal, dictará, en general, las disposiciones que considere oportunas, a fin de apartar al menor de un peligro o de evitarle perjuicios".

\section{II.3. Requisitos materiales}

Como es bien sabido, el consentimiento cuenta, al menos, con dos acepciones: de una parte, puede considerarse como una emisión de voluntad, libre y espontáneamente expresada y, de otra, como la decisión emitida por el agente de conocer y aceptar el objeto sobre el que consiente. Teniendo ello en cuenta el consentimiento informado requiere que previamente el sujeto que lo expresa haya reflexionado y razonado sobre el objeto en el que recae y que sea perfectamente consciente de ese objeto negocial y de las consecuencias previsibles que derivan de la emisión de su voluntad mediante la prestación del mismo. De ahí que según ha reiterado también la Jurisprudencia ${ }^{30}$, el consentimiento haya de contar con los siguientes requisitos:

a) La capacidad: El paciente que ha de prestar el consentimiento ha de estar en pleno uso de sus facultades mentales. Si el sujeto no es capaz de comprender, difícilmente podrá prestar consentimiento válido alguno. Para el supuesto de sujetos que tengan esa capacidad restringida, tanto la LGS (art. 10.6.b) como la Ley 41/ 2002 (art. 9.3) atribuyen aquella decisión a los familiares o personas a él.

b) Momento: $\mathrm{Ha}$ de ser previo al inicio en todo caso de la intervención (art. 10.6 LGS y art. 2.2 de la Ley 41/ 2002).

c) Libre: Esto es, ha de estar carente de vicios, ya sea error, violencia o intimidación. El error, en la medida en que medie una información correcta es difícil que concurra.

30 En este sentido, la SAP de Málaga de 2 de diciembre de 2002 (JUR 2004|66771; Recurso 295/2003). 
d) Reconocible: El art. 10.6 LGS exigía la forma escrita. Tras la aprobación de la Ley 41/ 2002 la regla general es la forma verbal, si bien en las actuaciones de mayor alcance se exige la forma escrita. Y así el art. 8.2, tras potenciar como forma ordinaria del consentimiento la verbal, exceptúa, exigiendo la forma escrita en los casos de intervención quirúrgica, procedimientos diagnósticos y terapéuticos invasores y, en general, aplicación de procedimientos que suponen riesgos o inconvenientes de notoria y previsible repercusión negativa sobre la salud del paciente; puntualizando su apartado 30 que el consentimiento escrito del paciente será necesario para cada una de las actuaciones especificadas en el punto anterior de este artículo, dejando a salvo la posibilidad de incorporar anejos y otros datos de carácter general, y tendrá información suficiente sobre el procedimiento de aplicación y sobre sus riesgos.

e) Informado: Si el consentimiento es voluntario pero no es informado se invalida por sí mismo. Debe, por tanto, contener una cantidad suficiente de información para que el paciente (y en su caso, su representante) pueda tomar la decisión pertinente. Y si el consentimiento ha de ser libre, presupuesto de aquél ha de ser la información adecuada, en cantidad y en calidad, si bien no es preciso informar detalladamente acerca de aquellos riesgos que no tienen un carácter típico por no producirse con frecuencia ni ser específicos del tratamiento aplicado, siempre que tengan carácter excepcional o no revistan una gravedad extraordinaria. En este sentido, el art. 10.1 incluye como información básica los riesgos o consecuencias seguras y relevantes, los riesgos personalizados, los riesgos típicos, los riesgos probables y las contraindicaciones. Luego se volverá sobre esta cuestión. Pero con independencia de cuanto después se analizará, debe avanzarse que todo consentimiento informado deberá contener los siguientes criterios de información:

a) Naturaleza de la intervención: en qué consiste, y qué se va hacer.

b) Objetivos de la intervención: para qué se hace.

c) Beneficios de la intervención: qué mejoría espera obtenerse.

d) Riesgos, molestias y efectos secundarios posibles, incluido el riesgo de no hacer la intervención.

e) Alternativas posibles a la intervención propuesta.

f) Explicación breve del motivo que lleva al donatario a elegir a ésta y no otras 
g) Posibilidad de retirar el consentimiento de forma libre cuando lo desee

Por último, además de cuidar los aspectos de cantidad y calidad en la información, no es menos importante cómo se facilita ésta al paciente. En cada momento será preciso modular la cantidad de información, siendo paulatino y progresivo el contenido en relación a cuestiones como el pronóstico, el diagnóstico, el estado emocional, así como las expectativas y el deseo de saber del paciente (SAP de las Islas Baleares 3 de febrero de 2003'11).

\section{II.4. Requisitos de contenido}

a) Objetividad, veracidad, claridad y suficiencia en la información

Como se ha dejado afirmado más arriba, el consentimiento prestado por el enfermo o sus parientes ha de ser informado de modo tal que pueda con él cumplirse la finalidad que le es propia, es decir, la de proporcionar a quien es titular del derecho a decidir los elementos adecuados para tomar la decisión que considere más conveniente a sus intereses (STSS 23 de noviembre de $2007^{32}$, de 4 de diciembre de $2007^{33}$ y de 18 de junio de $2008^{34}$ ). Sin embargo, junto a ello, el propio TS (STS de 16 de diciembre de 199735) declaró la dificultad de establecer de forma apriorística el modo de alcanzar estas cualidades en la información que se presta al paciente en tanto que no era posible fijar a priori su contenido, si bien, estableció unos mínimos: las características de la intervención quirúrgica; ventajas e inconvenientes de dicha intervención; riesgos de la misma, proceso previsible del post-operatorio y contraste con la residual situación ajena. Tal información deberá comprender, para no incurrirse en responsabilidad, el diagnóstico de la enfermedad o lesión que se padece, el pronóstico que de su tratamiento puede esperarse y los riesgos del mismo.

31 JUR 2003|148063; Recurso 753/ 2002.

32 RJ 2008|24; Recurso 4469/ 2000.

33 RJ 2008\41; Recurso 4241/ 2000.

34 RJ 2008\4256; Recurso 3421/ 2001.

35 RJ 1997/8690. 
Y junto a ello, la forma de facilitarla al paciente y, en su caso, a la familia, que habrá de hacerse de forma clara, objetiva y adecuada al procedimiento que se va a utilizar y las circunstancias concretas. En definitiva, la información habrá de ser comprensible, razonable y suficiente (SSTS 16 de diciembre de $1997^{36}, 31$ de marzo de 200437, 23 de julio ${ }^{38}$ y 18 de diciembre de $2003^{39}, 15$ de septiembre de $2003^{40}$ y 12 de enero de $2001^{41}$ ). El problema se centra en determinar cuándo se ha ofrecido la información en contenido suficiente para que resulte exoneradora de responsabilidad de la Administración primero $y$, en caso de una eventual acción de regreso, del facultativo. Para ello la Jurisprudencia realiza una labor de contraste entre el contenido y amplitud de esa información y el estándar de funcionamiento del servicio. Veamos al gunos ejemplos. En el supuesto fáctico que dio lugar a la STSJ de Valencia de 24 de diciembre de $2003^{42}$ el consentimiento de la paciente que aparecía en el documento de consentimiento informado se hacía constar: "Doña..., que precisa intervención quirúrgica, aceptando todos los riesgos inherentes a la misma, los cuales le han sido suficientemente y claramente explicados, autoriza al cirujano que realice la intervención para que, ante posibles hallazgos o incidentes operatorios imprevistos actúe libremente, según su leal saber y entender". Estos eran sus términos textuales, y de su análisis y examen el Tribunal concluye que: "en él consta la firma de la recurrente, la de una enfermera o responsable pero no la del facultativo que va a practicar la intervención, ni tampoco qué clase de cirugía se va a practicar en concreto". Es más, "existe un formulario genérico y vago respecto de lo que hasta el momento se ha expuesto como exigible, toda vez que, por lo que se refiere al contenido, no alude en particular al tipo de operación que se le iba a practicar, con exposición de su naturaleza, riesgos, garantías y secuelas, por citar unos parámetros mínimos; es más podría ser adaptable a cualquier tipo de intervención quirúrgi-

36 RJ 1997\8690; Recurso 3162/ 1993

${ }^{37}$ RJ 2004|2323; Recurso 1572/ 1998.

${ }^{38}$ RJ 200315462.

39 RJ 2003|9302; Recurso 766/ 1998.

40 RJ 200316418.

41 RJ 2001|3; Recurso 3688/ 1995.

42 JUR 2004|65026; Recurso 478/ 2001. 
ca y no consta estar practicada por facultativo, aunque no sea quien va a realizar la concreta intervención. Estas notas de generalidad y falta de concreción determinan un incumplimiento de la lex artis ad hoc, por infracción del deber de informar". Lo que realmente contenía este consentimiento informado -cabe añadir- era una "patente de corso" con el que su redactor pretendía exonerar al hospital y al facultativo de cualquier suerte de responsabilidad pasara lo que pasara.

O tro ejemplo paradigmático nos lo ofrece la SAP de Madrid de 16 de mayo de $2005^{43}$. En este caso, para reducir la miopía y el astigmatismo de sus ojos, el reclamante se sometió a una intervención quirúrgica de queratotomía radial, por indicación del cirujano oftalmólogo que la practicó. Como explicita la sentencia, el desarrollo del postoperatorio condujo a una severa hipermetropía y astigmatismo residuales a la intervención, de una evolución tan negativa que no respondió a una nueva intervención correctora, lo que finalmente le obligó a un trasplante de córnea, lo que no impidió una importante reducción de la visión en ambos ojos, junto a otras secuelas en el ojo derecho, lagrimeo constante, pérdida de la visión binocular y la visión de halos alrededor de las luces, aparte de un estrés pos traumático y un síndrome ansioso depresivo grave y crónico. En ambas intervenciones ( salvo en la del trasplante de córnea), el documento firmado por el paciente se limitaba a decir: "H e sido informado de la naturaleza y diagnóstico de mi proceso ocular. Doy el consentimiento informado para que me sean realizadas las pruebas tanto exploratorias como quirúrgicas para la resolución de mi afectación ocular". O bviamente este consentimiento es claramente insuficiente en su contenido, por lo que la sentencia estima que con él se ha incumplido el deber de información que exige la lex artis ad hoc, pues la exposición de los dos referidos documentos es más bien parca y lacónica y de sentido eminentemente abstracto e inconcreto, y en modo alguno revelan que se le hiciera saber la existencia de técnicas alternativas a la que se le iba a aplicar, ni de los riesgos y efectos secundarios de esta cirugía, entre los que se encontraban los problemas de cicatrización excesiva o defectuosa. Por tanto, afirma la sentencia, la información proporcionada dista de ser la oportuna y razonable que exigía la naturaleza de la intervención, con lo que el enfermo no pudo decidir consciente, libre y con pleno conocimiento sobre ellas, ni sobre si se sometía o no a la intervención.

${ }^{43}$ AC 2005\1089, Recurso 187/ 2004. 
Pero frente a esta clara insuficiencia de la información, también la Jurisprudencia (STS de 4 de abril de $2000^{44}$ y STSJ de Valladolid de 11 de enero de $2008^{45}$ ) se hace eco de que una información excesiva puede resultar desmesurada y en un padecimiento innecesario para el enfermo (de "auténtica cámara de los horrores" se ha llegado a calificar). Por ello se hace preciso interpretar en términos razonables este deber legal puesto que su aplicación rígida dificultaría el ejercicio de la función médica.

b) Riesgostípicos

El art. 10.1 de la Ley 41/ 2002 incluye como información básica que debe proporcionársele al paciente, antes de recabar su consentimiento escrito, la siguiente:

a) Las consecuencias relevantes o de importancia que la intervención origina con seguridad.

b) Los riesgos relacionados con las circunstancias personales o profesionales del paciente.

c) Los riesgos probables en condiciones normales, conforme a la experiencia y al estado de la ciencia o directamente relacionados con el tipo de intervención.

d) Las contraindicaciones.

Sobre este particular la Jurisprudencia insiste en que, si bien el deber de informar no tiene carácter absoluto y omnicomprensivo, debe extenderse a los riegos y complicaciones típicos, que no son otros que los eventuales pero previsibles e incluso frecuentes, asociados e inherentes a una intervención diagnóstica o terapéutica, esto es, los riesgos normalmente ligados al acto como posibles conforme a una razonable previsión y que pueden presentarse durante y después de ella, para que, con base en tal conocimiento, el paciente pueda tener posibilidad de valorar por él mismo, prestar su asentimiento 0 conformidad o, por el contrario, desistir de la intervención (SAP Barcelona de 12 de abril de $2005^{46}$ ). De forma singular se intensifica esta obligación de in-

\footnotetext{
${ }^{44}$ RJ 2000|3258; Recurso 8065/ 1995.

45 JUR 2008|107550; Recurso 973/ 2003.

${ }^{46}$ JUR 2005|126893; Recurso 861/ 2004.
} 
formar sobre ello cuando, además, su producción, más que previsible, resulta inevitable. A sensu contrario, no existe la obligación de informar sobre los riesgos atípicos dada su excepcionalidad, imprevisibilidad o infrecuencia (SSTS de 28 de diciembre de $1998^{47}$, de 15 de noviembre de $2006^{48}$, de 17 de abril de $2007^{49}$, de 23 de octubre de $2008^{50}$, STSJ del País Vaco de 25 de febrero de 200851, SAP de Barcelona de 17 de enero de $2003^{52}$ y de Madrid de 18 de febrero y de 4 de noviembre de $2008^{53}$ ), si bien esta exoneración de información se excepciona como después veremos, en el caso de la medicina satiffactiva o no necesaria, en la que la información debe ser objetiva, veraz, completa y asequible, y comprender las posibilidades de fracaso de la intervención, es decir, el pronóstico sobre la probabilidad del resultado, y también cualesquier secuela, riesgos, complicaciones o resultados adversos que se puedan producir, sean de carácter permanente o temporal, con independencia de su frecuencia, dada la necesidad de evitar que se silencien los riesgos excepcionales ante cuyo conocimiento el paciente podría sustraerse a una intervención innecesaria o prescindible o de una necesidad relativa (SSTS de 23 de mayo de $2007^{54}$ y de 22 de noviembre de $2007^{55}$ ).

Sin embargo, ha de advertirse que la frecuencia de la producción del riesgo, en términos estadísticos no tiene por qué resultar directamente proporcional a la previsibilidad de que se materialice de forma efectiva puesto que existen riesgos de esta naturaleza que raramente se dan y cuya producción se hace depender en gran medida de las circunstancias y características de un ca-

47 RJ 1998|10164; Recurso 2134/ 1994.

${ }^{48}$ RJ 200618059.

49 RJ 2007\3541.

${ }^{50}$ RJ 2008|5789; Recurso 870/ 2003.

51 JUR 2008|166159; Recurso 185/ 2005.

${ }^{52}$ AC 2003|1256; Recurso 965/ 2002.

${ }^{53}$ AC 2008|854; Recurso 588/ 2007 y AC 2008|2109; Recurso 369/ 2007.

54 RJ 2007/3273; Recurso 1940/ 2000.

55 RJ 2007/8651; Recurso 4358/ 2000. 
so concreto. Dicho en otros términos: lo importante no es ya la frecuencia estadística como la tipicidad del riesgo. Sin embargo, y pese a ello, la frecuencia o probabilidad de sufrir un determinado daño acentúa la obligatoriedad de la información y, en este sentido, que habrá de informarse muy particularmente de los siguientes riesgos: En primer lugar, de aquéllos que, aunque no sean frecuentes en el resto de la población, sin embargo son probables según la situación personalizada y actual del paciente en cuestión. En segundo lugar, de los infrecuentes pero que son especialmente graves y sean inherentes y posibles en la intervención o procedimiento que va a llevarse a cabo. Y, en tercer lugar, habrá de informarse con mayor intensidad cuanto menos posibilidades existan de obtener un resultado satisfactorio con la intervención.

En cualquier caso, información suficiente no significa agotadora ni extremadamente exhaustiva hasta el extremo, como afirma la SAP de Vizcaya de 8 de octubre de $2008^{56}$, de tener que detallar hasta el más mínimo peligro que se pueda correr, ya que, en un orden normal de entendimiento, es por todos sabido que la cirugía supone una agresión corporal, controlada en condiciones ordinarias, pero que la casualidad o el destino puede alterar, ocasionando lesiones que la estadística clínica desprecia por improbables.
c) Personalización de la información (el problema de losformularios impresos).

La Jurisprudencia viene insistiendo en la necesidad de personalizar la información según la situación de cada enfermo. Esta obligatoriedad convierte a la información que ha de suministrarse al paciente, no un mero formalismo, sino en una exigencia con contenido sustantivo propio, lo que en la práctica se ha de traducir en la elaboración de un documento al efecto y no en formularios y protocolos, a veces excesivamente largos y complejos que son concebidos por el propio paciente como ostensiblemente inadecuados y su entrega, como una auténtica "agresión" (STS de 4 de abril de $2000^{57}$ ). Tanto es así que han llegado a calificarse por la Jurisprudencia como meros "documentos impresos de adhesión" (SAP de Barcelona de 13 de marzo de 200758)

\footnotetext{
${ }^{56}$ AC 2008|1966; Recurso 314/ 2008.

57 RJ 2000|3258; Recurso 8065/ 1995.

${ }^{58}$ AC 2007/732; Recurso 551/ 2007.
} 
o como "documentos estándar" o "documentos tipo" (SAP de Vizcaya de 8 de octubre de $2008^{59}$ ), o incluso como simples y escuetos formularios, más próximos a un mero acto administrativo, que médico (STS de 15 de noviembre de 200660).

De ahí que la STS de 29 de mayo de $2003^{61}$ y la SAP de Alicante de 23 de octubre de $2007^{62}$ hayan acabado por afirmar que en ningún caso el consentimiento prestado mediante los mismos, cuando carecen de todo rasgo informativo adecuado, pueden servir para conformar una debida y correcta información, al tratarse de "documentos ética y legalmente inválidos que se limitan a obtener la firma del paciente, pues aun cuando pudieran proporcionarle alguna información, no es la que interesa y exige la norma como razonable para que conozca la trascendencia y alcance de su patología, la finalidad de la terapia propuesta, con los riesgos típicos del procedimiento, los que resultan de su estado y otras posibles alternativas terapéuticas". La información ha de ser, en definitiva, "básica y personalizada, y no un simple trámite administrativo, y en la que también el paciente adquiera una participación activa, para, en virtud de la misma, consentir o negar la intervención" (STS 15 de noviembre de $2006^{63}$, ST SJ de Valladolid de 11 de enero de $2008^{64}$, SAP Madrid de 4 de noviembre de $2008^{65}$ y Sentencia del Juzgado de Santander de 10 de febrero de $\left.2003^{66}\right)$.

En esta línea, la SAP de Madrid de 27 mayo $2008^{67}$ rechaza el consentimiento que tenía firmado la actora al resultar tremendamente genérico y

${ }^{59}$ AC 2008|1966; Recurso 314/ 2008.

60 RJ 200618059.

${ }^{61}$ RJ 2003|3916.

${ }^{62}$ AC 2007/2106; Recurso 390/ 2007.

63 RJ $2006 \mid 8059$.

64 JUR 2008|107550; Recurso 973/ 2003.

65 AC 2008|2109; Recurso 369/ 2007.

66 JUR 2003160027.

${ }^{67}$ AC 2008|1159. 
no personalizado, ya que no aportaba la información precisa sobre la trascendencia y alcance de "su" patología, la finalidad de la operación propuesta, y la constancia de los riesgos del procedimiento, los que resultarían de "su" estado y otras posibles alternativas terapéuticas. Del mismo modo, no se hacía "mención particularizada" de su concreta situación médica, ni concreción de los riesgos y posibles complicaciones del tratamiento, y sobre todo, aquéllos que podían resultar de su estado en particular, circunstancias éstas que conllevan la conclusión de "deficiencia del consentimiento informado".

Especialmente ilustrativa en este sentido fue la SAP de Vizcaya de 8 de octubre de 200868:

"no puede entender la Sala que el documento firmado por la actora obrante al folio 211 de los autos pueda considerarse como expresión válida de un consentimiento informado, y ello porque se trata de un mero impreso que se le somete a la firma, en el que no se especifica ni la intervención de que va a ser objeto la demandante, ni otra cuestión que los riesgos y complicaciones inherentes a un procedimiento quirúrgico y postquirúrgico así como la autorización para la realización de transfusiones de sangre y el consentimiento para cualquier tipo de anestesia general local o lo corregional que fuere preciso y las posibles complicaciones que de ello pudieran derivarse, pero como hemos dicho ni se especifica la intervención de que va a ser objeto ni cuáles son las complicaciones que pueden producirse como consecuencia de dicha intervención, por tanto no puede considerarse como documento bastante para acreditar que se produjo la información, información que le incumbe exclusivamente al médico que va a realizar la intervención, lo que implica y supone que no ha existido consentimiento informado (... ) Del mismo modo no se hace mención particularizada de la situación médica del enfermo ni concreción de los riesgos y posibles complicaciones de un tratamiento que al no tener carácter de extrema urgencia podía ser renunciado, en conclusión el documento firmado por la actora es un modelo de formulario estándar, documento tipo, que en consecuencia carecería de relevancia y virtualidad jurídica, por cuanto que, como se ha puesto de relieve no contiene el riesgo típico y más grave de la intervención que sería la posibilidad de inutilidad de la misma y la necesidad de reiteración como ocurrió en el presente caso de nue-

${ }^{68}$ AC 2008|1966; Recurso 314/ 2008. 
vas intervenciones quirúrgicas para solventar el problema del conducto biliar, tampoco se informa sobre posibles tratamientos terapéuticos alternativos que han de facilitarse incluso cuando no exista alternativa al método quirúrgico, por todo ello no puede apreciarse en forma alguna que la actora y hoy recurrente conociera la trascendencia y alcance de su patología, los riesgos típicos y posibles del tratamiento, y sobre todo aquellos que podían resultar de su estado en particular, lo que conlleva a la conclusión de la deficiencia del consentimiento informado realizado por el Dr. al no haber informado a la demandante de los riesgos típicos de la concreta intervención médico-quirúrgica y al haberse materializado tras la intervención los referidos riesgos, lo que conlleva a tenor de la jurisprudencia de nuestro Tribunal Supremo que la trascendencia del incumplimiento del deber de información impuesto por la Ley, debe desvincularse del cumplimiento del oficio técnico del cirujano o del médico. Debiendo valorarse en cuanto a proceder antijurídico, la privación del derecho del paciente a obtener la información esclarecedora previa al consentimiento, con ello también establece el Tribunal Supremo la autonomía de la responsabilidad derivada de la ausencia de información, con lo que no es necesaria la existencia de relación causal entre la omisión de informar y el daño producido por la actividad médica, indicando que el daño que fundamenta la responsabilidad resulta de haberse omitido la información previa al consentimiento, así como de la posterior materialización del riesgo previsible".

Cuestión distinta es la forma que ha de adoptarse para efectuarlo, es decir, la constancia que ha de tener el consentimiento, si oral o escrita. La LGS exigía hacerlo por escrito, como regla general, mientras que la actual Ley 41/ 2002 en su art. 8.2 invierte los términos, considerando que deberá hacerse oralmente, quizá impulsada por el ánimo de dinamizar la relación médicopaciente, facilitar su proximidad y permitir que el médico responsable adecúe el contenido de la información a las circunstancias y requerimientos del paciente. Deberá, sin embargo, adoptar la forma escrita en los casos siguientes: intervención quirúrgica, procedimientos diagnósticos y terapéuticos invasores y, en general, en caso de aplicación de procedimientos que suponen riesgos o inconvenientes de notoria y previsible repercusión negativa sobre la salud del paciente.

En consecuencia, la forma elegida para ofrecer la información -oral o escrita- no es constitutiva ni esencial. Por tanto, no condiciona su validez y mucho menos su eficacia, por lo que la exigencia de la constancia escrita tiene un 
mero valor ad probation em (SSTS de 2 octubre $1997^{69}, 26$ enero $^{70}$ y 10 noviembre $1998^{71}$, de 2 noviembre $2000^{72}$, de 2 de julio de $2002^{73}$, de 29 de septiembre de $2005^{74}$ y de 26 de junio de $2006^{75}$, entre otras), esto es, facilita su prueba, cuya carga corresponde al Centro hospitalario y, en su caso, al médico responsable de efectuarla. Es más, como reconoce la SAP de las I slas Baleares 3 de febrero de $2003^{76}$, la exigencia de que la información se dé, además, en forma escrita no puede ser predicada de toda la información suministrada, pues, es obvio que la continuidad de la información se compadece mal con ella. Por ello, la información escrita ha de requerirse sólo de aquellos hitos fundamentales, como es el diagnóstico, las alternativas terapéuticas y el informe de alta. En cualquier caso, la información debe ser oral si el paciente no sabe leer ni escribir (SAP Barcelona de 12 de abril de $2005^{77}$ ).

Ahora bien, la libertad de forma que se predica para suministrar la información no empece la necesidad (que no la exigencia) de que, de no hacerlo en forma escrita, quede constancia tanto de la información dada como del

69 RJ 1997\7405; Recurso 1104/ 1993.

70 RJ 1998|550; Recurso 2629/ 1993

71 RJ 1998/8819; Recurso 614/ 1995.

72 RJ 2000|9206; Recurso 3161/ 1995.

73 RJ 200215514; Recurso 2769/ 1996.

74 RJ 2005|8891; Recurso 189/ 1999.

75 RJ 2006\5554; Recurso 4072/ 1999.

76 JUR 2003|148063; Recurso 753/ 2002.

77 JUR 2005\126893; Recurso 861/ 2004. La sentencia afirma que: en este caso, "mal se le podía dar a leer un documento en el que constara toda la información precisa sobre el diagnóstico, el pronóstico y las posibles alternativas, pues es claro que la paciente no podría leerlo por sí sino que le tenía que ser leído por otra persona, bien del entorno familiar o persona extraña o del equipo médico o auxiliar de la clínica, lo que no consta que se hiciera, por lo que ante la previsión legal existente en el momento de la intervención ( Ley General de Sanidad), y no obstante la práctica habitual en aquella fecha de información verbal (...) debió extremarse por el médico interviniente la diligencia tendente al correcto entendimiento por la persona que iba a ser intervenida de la actuación médica que se iba a llevar a cabo y de las posibles alternativas respecto a la misma (...)". 
consentimiento emitido, en la historia clínica del paciente y el resto de la documentación hospitalaria que le afecte (SAP de Madrid de 19 de diciembre de 200778).

\section{II.5. Requisitos de tiempo}

El consentimiento informado no deja de ser un acto intelectual y, por tanto, que requiere que se efectúe con el suficiente grado de reflexión por parte de quien recibe la información, para que después se encuentre en condiciones adecuadas de decidir y emitir su consentimiento. Ni la Ley ni la Jurisprudencia establecen cuál deba ser el lapso de tiempo preciso para llevar a cabo esta labor pues, obviamente, ello dependerá de las circunstancias personales y de la urgencia de la intervención. Por ello, se limita a resaltar la necesidad de hacerlo con antelación y dedicación suficiente (STS de 15 de noviembre de $2006^{79}$ ) y proporcional al tipo de intervención -necesaria o satisfactiva, o de mayor o menor urgencia-. Destaca en este sentido la STS de 29 de julio de $2008^{80}$ que considera inválido el consentimiento dado por un paciente estando ya en quirófano y justamente en el momento previo a ser intervenido quirúrgicamente. Tampoco es de recibo que la información sea ofrecida en forma de impreso en la propia recepción o Administración del Centro, como si se trata de un mero trámite administrativo (Juzgado Primera Instancia de Barcelona de 18 de abril de $2006^{81}$ ). Como bien afirma Guerrero Zaplana ${ }^{82}$, "facilitar la información sin tiempo para prestar el consentimiento es tanto como privar de la información".

Por otra parte, la intervención ha de ser continuada, carácter que sólo puede referirse a la que afecta a la evolución del proceso, lo que quiere decir que el paciente ha de ser informado de éste con una asidua periodicidad (SAP de Baleares de 3 de febrero de $2003^{83}$ ) si las circunstancias así lo requieren, lo que

78 AC 2008|81466; Recurso 79/ 2007.

${ }^{79}$ RJ $2006 \mid 8059$.

80 RJ 2008/4638; Recurso 541/ 2002.

${ }^{81}$ AC 2006/409; Procedimiento no 411/ 2005.

82 GUERRERO ZAPLANA, J. El consentimiento informado. Su valoración en la Jurisprudencia. VaIladolid, Lex Nova, 2004, pág. 96.

83 JUR 2003|148063; Recurso 753/ 2002. 
será especialmente necesario en las enfermedades crónicas y en aquéllas que requieran intervenciones sucesivas y distintas en el tiempo, pues no debe olvidarse que la información ha de ser actual y específica para cada intervención.

\section{LA CARGA DE LA PRUEBA DEL CONSENTIMIENTO}

El aspecto más relevante de la forma que ha revestir la comunicación es su trascendencia al campo de la carga de la prueba, esto es, en la determinación de si corresponde la carga de la prueba (on us probandi) a quien formula la reclamación patrimonial o al Centro hospitalario, y, en consecuencia, quién ha de soportar las consecuencias de la falta de acreditación procesal de que la necesaria información ha sido suministrada cuando, afirmada por el Centro, es negada por el paciente.

Bien sabido es que, según una clásica doctrina jurisprudencial, ha de distinguirse a tal efecto entre hechos constitutivos de la pretensión y los impeditivos, obstativos o extintivos, atribuyendo la carga de probar los primeros al que reclama y la de los segundos a quien los opone (art. 217.1 LEC), doctrina ésta que la más moderna Jurisprudencial ha venido completando con la doctrina de la facilidad o proximidad de la prueba (art. 217.6 LEC), de forma y manera que con independencia de a qué categoría pertenezcan los hechos discutidos, su prueba corresponde a aquélla parte que está más próxima a los medios probatorios o que le es más fácil levantar la carga probatoria ${ }^{84}$. Por virtud de este criterio, desde la STS de 16 de octubre de $1998^{85}$ la carga de la

\footnotetext{
${ }^{84}$ Resulta en este sentido oportuna la cita de la STC 7/ 1994 de 17 de enero que afirma: "cuando las fuentes de prueba se encuentran en poder de una de las partes en litigio la obligación constitucional de colaborar con los Tribunales en el curso del proceso, conlleva que dicha parte es quien debe aportar los datos requeridos a fin de que el órgano judicial pueda descubrir la verdad". En el ámbito sanitario, no sólo la facilidad probatoria la tendrá la parte demandada, sino que en ocasiones ha reconocido el propio TS que sobra ella debe recaer el deber procesal de probar puesto que "por sus propios conocimientos técnicos en la materia litigiosa, y por los medios poderosos a su disposición, gozan de una posición procesal mucho más ventajosa que la de la propia víctima, ajena al entorno médico y, por ello, con mucha mayor dificultad a la hora de buscar la prueba, en posesión, muchas veces, sus elementos de los propios médicos o de los centros hospitalarios a los que, qué duda cabe, aquéllos tienen mucho más fácil acceso por su profesión" (SSTS de 2 de diciembre de 1996 [RJ 1996|8938; Recurso 404/ 1993] y de 29 de noviembre de 2002 [RJ 2002/10404; Recurso 1270/ 1997]).
}

85 RJ 1998/7565; Recurso 2165/ 1994. 
prueba de la satisfacción del derecho de información corresponde al Centro sanitario, pese a que la falta de cumplimiento del deber de informar es un hecho constitutivo de la pretensión que por ella se le dirija86. Y junto a él, otro no menos importante y que viene a complementarlo: la imposibilidad de probanza de los hechos negativos ( prueba diabólica) en tanto que la inexistencia de información es un hecho de este tipo y cuya demostración no puede imponerse a quien lo alega so pena de poner a su cargo una prueba que pudiera calificarse de perversa, y como tal contraria al principio de tutela efectiva por implicar indefensión (STC de 10 de enero de 1994, STS de 18 de mayo de $2006^{87}$ y SAP de Vizcaya de 8 de octubre de $2008^{88}$ ).

La regla, sin embargo, no es absoluta, pues la propia Jurisprudencia matiza este desplazamiento de la carga de la prueba a través de dos nuevos mecanismos que sirven de contrapeso: uno, por vía de presunciones y otro, mediante la posibilidad de que sea el propio paciente el que solicite más caudal de información. A través del primero, los Tribunales, a la vista del material probatorio incorporado en Autos, pueden llegar a la conclusión de que la información y el ulterior consentimiento tuvieron lugar -a veces de forma expresa y otras de forma tácita o presunta-, pese a su falta de constancia escrita. Es lo que ocurrió en la STS de 30 de abril de $2007^{89}$ en que tras ponderar las diversas circunstancias concurrentes en el caso llega a la conclusión de que la no aportación de documento escrito alguno no supone incumplimiento del deber de información, puesto que así lo evidencia el hecho de la absoluta necesidad de la intervención y de que la técnica empleada era habitual y portadora de claras ventajas y beneficios para el paciente respecto de alternativas operatorias anteriores. Aplica también la prueba de presunciones la STS de 26 de noviembre de $2004^{90}$ en la que el Tribunal llega a la conclusión de que la

86 SST S de 25 de abril de 1994 (RJ 1994|3073), de 19 de abril de 1999 (RJ 1999|2588; Recurso 3362/ 1998), de 7 de marzo de 2000 (RJ 2000|1508; Recurso 1694/ 1995), 12 de enero de 2001 (RJ 200113; Recurso 3688/ 1995), 17 de noviembre de 2005 (RJ 2005\7636), 18 de mayo de 2006(RJ 200614724; Recurso 3337/ 1999), 26 de junio de 2006 (RJ 200615554; Recurso 4072/ 1999) y de 28 de noviembre de 2007 (RJ 2007/8428; Recurso 4889/ 2000).

${ }^{87}$ RJ 200614724; Recurso 3337/ 1999.

${ }^{88}$ AC 2008|1966; Recurso 314/ 2008.

${ }^{89}$ RJ $2007 / 2397$.

90 RJ 2005|22; Recurso 280/ 2001. 
información y el consentimiento existieron dado que si bien existía otra alternativa distinta para paliar el padecimiento de la actora ésta era mucho más traumática y cruenta que la empleada.

La segunda vía, es decir, la exigencia de que sea el propio paciente el que solicite, no ya "la información", sino "más información" ha sido en ocasiones apuntado por la Jurisprudencia si bien nunca cuando la omisión de información ha sido total y absoluta. Así lo afirma la SAP de Vizcaya de 8 de octubre de 200891: "no se puede desplazar al paciente la obligación de exigir una información más completa, ante la insuficiencia de la que se ofrece".

IV. LA EXIGENCIA DEL DEBER DE INFORMACIÓN Y SUS DISTINTOS GRADOS: EL CONSENTIMIENTO INFORMADO EN LA MEDICINA CURATIVA O ASISTENCIAL, EN LA MEDICINA VOLUNTARIA O NO NECESARIA YEN LA MEDICINA ESTÉTICA

El consentimiento informado presenta distintos grados de exigencia según se trate de actos médicos realizados con carácter curativo o se trate de la Ilamada medicina satisfactiva. Es lugar común en este punto distinguir entre una y otra afirmando que la primera (la medicina necesaria, curativa, o asistencial) se desarrolla en el ámbito propio de los arrendamientos de servicios, dando lugar a una obligación de medios, a diferencia de la satisfactiva en que la obligación es de resultado, con mayores exigencias en cuanto a la prestación de la asistencia sanitaria y en cuanto a la información, lo que plantea sin duda la delicada labor de distinguir entre ambas en cada caso concreto. Y de todos, probablemente el aspecto más polémico específico del deber de información es el relativo al alcance o la distinta intensidad que ha de tener lugar, es decir, de qué hay que informar y cuánta cantidad de información ha de suministrarse al paciente, 0 , en su caso, cliente -según se trate de medicina necesaria o de medicina satisfactiva- $y$, especialmente en cuanto a las alternativas terapéuticas y los riesgos que cada una comporta. A estos efectos, conviene comenzar por distinguir entre un tipo y otro de medicina para abarcar después el estudio del alcance y contenido concreto de la información que ha de ser suministrada en cada uno de los supuestos.

${ }^{91}$ AC 2008|1966; Recurso 314/ 2008. 
Jurisprudencialmente ${ }^{92}$ viene distinguiéndose, por un lado, la actuación médica o médico-quirúrgica que trata de curar o mejorar a un paciente, de aquélla otra en que se acude a un profesional para obtener, en condiciones de normalidad de salud, algún resultado que voluntariamente se quiere conseguir. En este orden, la Jurisprudencia ha distinguido ambos supuestos hasta el extremo de calificar el contrato de arrendamiento de servicios el que une al paciente con el médico en el caso de la medicina necesaria o curativa. En ella se persigue la curación del paciente, y por ello se afirma que es una medicina de medios, no de resultados. Por tanto, en ella la diligencia del médico consiste y se limita en emplear todos los medios a su alcance para conseguirla, se logre o no finalmente. En definitiva, ha de partirse del axioma de que se cumple con lo que es exigible cuando se aplican cuantos medios son precisos para la curación del enfermo. Cuando ésta se ejerce sobre el paciente ( y así lo recuerda la Jurisprudencia) ha de tenerse presente tanto la naturaleza mortal del hombre, como los niveles a que llega la ciencia médica -insuficientes para la curación de determinadas enfermedades- y, finalmente la circunstancia de que no todos los individuos reaccionan de igual manera ante los tratamientos de que dispone la medicina actual - lo que hace que algunos de ellos, aún resultando eficaces para la generalidad de los pacientes, puedan no serlo para otros-; todo lo cual impide reputar al aludido contrato como un arrendamiento de obra, vínculo que obligaría a la consecución de un resultado, la curación del paciente, que, en muchos casos, ni puede, ni podrá nunca conseguirse (SSTS de 27 de junio ${ }^{93}$ y de 12 de septiembre de $2001^{94}$ ).

Distinto por completo es el supuesto en que el interesado acude al médico, no para la curación de una dolencia patológica, un padecimiento o un trastorno físico, sino para conseguir una transformación satisfactoria, el mejoramiento de su aspecto físico o estético, en cuyo caso, sin perder su carácter de arrendamiento de servicios, puede configurarse como un arrendamiento de obra. Dicho de otra forma: una obligación de hacer (la intervención) se convierte en una obligación de dar (el resultado pretendido). De ahí que se acentúe en este caso la obligación del facultativo de obtener un resultado para el pacien-

92 Así, por ejemplo, entre otras muchas, puede consultarse la STS de 11 de mayo de 2001 (RJ 200116197; Recurso 1044/ 1996).

93 JUR 2001|267298.

94 JUR $2001 / 291151$. 
te 0 , si se quiere, la exigencia de una mayor garantía en la obtención del resultado que se persigue (SAP de Tenerife de 28 de octubre de $2000^{95}$ y SAP de Valencia de 10 de julio de $2000^{96}$ ). De ahí que esta obligación, que es todavía de medios, se intensifica, haciendo recaer en el facultativo, no ya sólo, como en los supuestos de medicina curativa, la utilización de los medios idóneos para tal fin, así como la obligación de informar y con mayor fuerza aún, al cliente -que no paciente-, tanto del posible riesgo que la intervención acarrea -especialmente si ésta es quirúrgica- como de las posibilidades de que la misma no comporte la obtención del resultado que se busca, y de los cuidados, actividades y análisis que resulten precisos para el mayor aseguramiento del éxito de la intervención (SST S de 25 de abril de $1994^{97}$ y 11 de febrero de $1997^{98}$ y de 28 de junio de $1999{ }^{99}$ ). Con todo, es preciso dejar advertido que esta consideración de la relación que une al paciente con el médico -0, mejor, con el Centro hospitalario- en la medicina satisfactiva como cercana al arrendamiento de obra es ciertamente excepcional y la Jurisprudencia la viene limitando a supuestos como la cirugía estética (SAP 28 de enero de 2008100), vasectomía (STS 25 de abril de 1994 ${ }^{101}$ ) y odontología (STS de 28 de junio de 1999102). En estos tres casos la obligación es de resultado, de forma que, fracasada la operación y no constando que al paciente se le informara de sus riesgos, procede la reparación patrimonial si concurren los requisitos que después se analizarán.

a) En la medicina curativa 0 asistencial

Como ya ha quedado avanzado, en este caso y con carácter general, puede afirmarse que no es menester informar agotadora, exhaustiva y detallada-

\footnotetext{
95 JUR 2001|27355.

96 JUR 20001286156.

97 RJ $1994 \mid 3073$.

98 RJ 1997/940; Recurso 527/ 1993.

${ }^{99}$ RJ 1999\4894; Recurso 3617/ 1994.

100 JUR 2008|114524; Recurso 811/ 2007.

101 RJ 1994|3073.

102 RJ 1999\4894; Recurso 3617/ 1994.
} 
mente acerca de aquellos riesgos que no tienen un carácter típico por no producirse con frecuencia ni ser específicos del tratamiento aplicado, siempre que tengan carácter excepcional o no revistan una gravedad extraordinaria (STS de 17 de abril de 2007103). Tal y como se advirtió más arriba, la exigencia de información se limita a los riesgos, secuelas y complicaciones más probables y graves que pueda suponer cada una de las alternativas terapéuticas, sin que pueda ser exigida una información exhaustiva de aquéllos que sean posibles pero remotos pues, como afirma la SAP de las Islas Baleares 3 de febrero de 2003104, "ello supondría la exigencia de un imposible".

Por otra parte, el deber de informar forma parte de los deberes generales a cumplir por el Centro H ospitalario, y sólo desaparece en supuestos de urgencias que impliquen riesgo vital o puedan causarle graves lesiones de carácter inmediato (ST S 24 mayo $1995^{105}$ y STS) de I slas Baleares de 30 de junio de 2005106).

\section{b) En la medicina voluntaria o no necesaria}

En lo que atañe a la llamada medicina satisfactiva, se requiere un mayor reforzamiento de la información, un "plus de información", que radica fundamentalmente en dos puntos concretos: en la advertencia de la probabilidad de que el resultado puede no ser conseguido y en una más amplia especificación en cuanto a los riesgos. Como se afirma en la STSI de Islas Baleares de 30 de junio de $2005^{107}$ en la medicina satisfactiva o voluntaria la libertad de opción por parte del paciente es evidentemente superior a la que tienen los pacientes sometidos a medicina necesaria, debiendo analizarse cuidadosamente si la información recibida fue la debida para prestar el consentimiento y la conformidad a la intervención, por cuanto se haya ponderado el riesgo de complicación con la innecesariedad de la operación.

\footnotetext{
103 RJ 2007/3541.

104 JUR 2003|148063; Recurso 753/ 2002.

105 RJ 1995\4262; Recurso 822/ 1992.

106 RJCA 2005|398; Recurso 1247/ 2001.

107 RJCA 2005|398; Recurso 1247/ 2001.
} 
Pues bien, partiendo de que en tales casos estamos en presencia de una obligación de resultado o asimilable a ella, la SAP de las I slas Baleares 3 de febrero de $2003^{108}$ se ha ocupado de determinar cómo ha de ser la información en estos casos y sobre qué puntos ha de versar:

- La información tiene que ser mucho más completa que en la medicina necesaria.

- Hay que explicar las consecuencias previsibles con mucha mayor minuciosidad, precisión y exactitud.

- Debe hacerse un informe claro y completo de los riesgos descartables, y cuáles no lo son, para que la persona que solicite la intervención -o los representantes legales en su caso- puedan hacer declaración expresa de que asumen los riesgos -inevitables- que se le hayan explicado claramente.

- Y que el documento tipo o estándar para hacer constar el consentimiento no esté prefijado, pues en cada caso ha de ser confeccionado por el responsable de la intervención, siendo aconsejable acompañar un dossier explicativo de todos los riesgos, y su evaluación estadística atendidas las circunstancias concretas de cada caso.

Por otra parte, la información que precede al consentimiento debe ser acompañada del Ilamado "consejo terapéutico", esto es, de la opinión del facultativo de cuál de las alternativas posibles que se han hecho saber al enfermo es la más adecuada y provechosa, pero, atención, dar un consejo no es sustituir al paciente en su decisión sobre la realización de la intervención o el tratamiento sino orientar sobre lo que, según su parecer, pudiera resultar más ventajoso.

c) En la cirugía estética

Dentro de la medicina satisfactiva merece singular atención la cirugía estética, también llamada "medicina perfectiva y voluntaria" en la que el paciente -para algunos- en estos supuestos, cliente-, no acude al médico por ausencia de salud, sino buscando la mejoría del aspecto físico o estético, por lo que en esos supuestos sigue existiendo la obligación de medios, pero también

108 JUR 2003|148063; Recurso 753/ 2002. 
la de obtener el resultado para lo que se contrata la actuación médica. ¿Significa ello que la no consecución del resultado lleva aparejado el deber de indemnizar? Obviamente no. No, al menos, sin la concurrencia de los requisitos que después se especificarán.

Lo que es evidente es que en este tipo de medicina se ha de acentuar la indispensable obligación de informar, tanto de los posibles riesgos como de los pormenores de la intervención, tales como de las posibilidades de que la misma no comporte la obtención del resultado querido, además de los cuidados y análisis que se precisarán. En definitiva, en estos casos la información ha de manifestarse en tal plenitud que las relaciones previas entre el cirujano y el cliente han de plantearse con todo su rigor y sin reserva al guna, advirtiendo de las circunstancias de lo que va a acontecer y sin eludir en modo alguno cualquier circunstancia por eventual que ésta sea y que pudiera frustrar el objetivo deseado por el cliente (SAP de las I slas Baleares 3 de febrero de 2003109).

Sólo siendo así se permite al interesado, paciente o cliente, conocer los eventuales riesgos para poderlos valorar y con base en tal información prestar su consentimiento o desistir de la operación, habida cuenta de la innecesaridad de la misma, lo que obliga a mantener un criterio más riguroso a la hora de valorar la información que en caso de que la que se ofrece en la medicina necesaria, porque la relatividad de la necesidad de someterse a una intervención de este tipo podría dar lugar en algunos casos a un silenciamiento de los riesgos excepcionales a fin de evitar una retracción de los pacientes a someterse a la misma (SSTS de 2 de julio de $2002^{110}$, de 21 de octubre de $2005^{111}$, 10 de mayo ${ }^{112}$ y 4 de octubre de $2006^{113}, 17$ de abril ${ }^{114}, 4$ de octubre ${ }^{115}$ y 22 de noviembre de $2007^{116}$ y otras muchas en ellas citadas). Por ello, si se pro-

${ }^{109}$ JUR 2003|148063; Recurso 753/ 2002.

110 RJ 200215514; Recurso 2769/ 1996.

111 RJ 2005|8547; Recurso 1039/ 1999.

112 RJ 2006|2399; Recurso 3476/ 1999.

113 RJ $2006 \backslash 6428$.

114 RJ 2007\3541.

115 RJ 2007\5352; Recurso 4813/ 2000.

116 RJ 2007/8651; Recurso 4358/ 2000. 
voca cualquier desvío o apartamiento de ese modelo elegido -siempre y cuando ello tenga una entidad objetivamente valorable-, cabe hablar de un desencadenante de una lesión antijurídica y provocante, por ende, de la responsabilidad patrimonial, pues, como afirma la STS de 26 de abril de 2007,117 con esta medicina lo que se pretende es "un resultado concreto que el médico oferta al cliente", respondiendo la demanda de los mismos -recordémoslo una vez más- no a imperiosa necesidad de la salud del enfermo, sino a su voluntad de tratar una mejora corporal, estética o funcional del propio cuerpo, por lo que el resultado en este tipo de cirugía "opera como autentica representación final de la actividad que desarrolla el facultativo, ya que su obtención es el principal cometido de la intervención".

Ello no implica que haya de responderse de cualquier resultado desafortunado puesto que no pueden descartarse los componentes aleatorios de riesgo que toda intervención médica puede llevar consigo, pero sí de aquéllos que no hubieran sido informados debida y cumplidamente (SAP 28 de enero de $2008^{118}$ ). Tal fue el caso de la STS de 2 de julio de $2002^{119}$. Se trataba de una operación de vasectomía en la que el paciente sufrió la pérdida de un testículo por atrofia. Comprobado que se trataba de una "complicación previsible y frecuente" y que de ello no había sido informado el paciente, el TS estima el derecho a ser indemnizado, no ya porque el deber de informar tenga carácter absoluto y omnicomprensivo, sino porque éste se extiende a este tipo de complicaciones dada su previsibilidad y de la que no sólo nada se dijo sino que se minimizaron los riesgos, pues se le había manifestado que "se trataba de una intervención sencilla y que simplemente sufriría unas ligeras molestias los primeros días". Ante este tipo de información, el TS afirma: "la información proporcionada no fue la oportuna y razonable en relación con la intervención y el usuario, pues no se le pusieron de relieve los eventuales riesgos, previsibles e incluso frecuentes, para poder ser valorados por el mismo, y con base en tal conocimiento prestar su asentimiento o conformidad o desistir de la operación, y ello era tanto más relevante si se tiene en cuenta que se que se trataba de una intervención quirúrgica, y de un supuesto de los que se denominan de medicina voluntaria (no curativa o satisfactiva) en los que la libertad de opción por parte del cliente es evidentemente superior a la que tienen los pacientes sometidos a la medicina necesaria o curativa".

117 RJ 2007/3176; Recurso 1919/2000.

118 JUR 2008|114524.

119 RJ 200215514; Recurso 2769/ 1996. 
Por último, y en cualquier caso, tanto se trate tanto de medicina necesaria como satisfactiva, el Centro, -obviamente personificado en la figura del médico responsable- deberá tener presente que cuanto más dudoso sea el resultado de una intervención y cuanto más grave y peligrosa sea, más caudal de información y más necesario resulta el previo consentimiento, preferiblemente por escrito, del paciente (SAP de Barcelona de 15 de enero de $2007^{120}$, STS) de Castilla y León, Valladolid, de 14 de mayo de $2008^{121}$ ).

\section{LA PRODUCCIÓN DE RIESGOS NO INFORMADOSY SU IMPU- TACIÓN}

A estas alturas fácil es llegar a la conclusión, que ya se dejó avanzada desde el principio, de que si bien la falta o deficiencia del consentimiento informado constituye título de imputación de responsabilidad, sin embargo éste no es suficiente, pues se requiere que se haya producido o materializado el riesgo del que no se había informado y del que, en consecuencia, no se había obtenido el consentimiento del paciente 0 , en su caso, del cliente. Y lo mismo sucede en su reverso: realizada una prestación médica y de la derivan unos daños que no le son los inherentes, típicos, propios ni traen en ella su causa ( por ejemplo, las que derivan de una falta de asepsia o de la utilización de un instrumental inadecuado ${ }^{122}$, insuficiencia o falta de coordinación objetiva del servicio ${ }^{123}$ o el hecho de dejar en el interior material quirúrgico ${ }^{124}$ ) la responsabilidad patrimonial viene de suyo pese a que exista consentimiento informado. EI TS lo ha dejado dicho con una claridad meridiana en SSTS de 3 y 10 de octubre de $2000^{125}$ y 10 de octubre de $2000^{126: ~ " E l ~ t i ́ t u l o ~ d e ~ i m p u t a-~}$

120 JUR 2007\192866; Recurso 238/ 2006.

121 JUR 2008|355989; Recurso 1536/ 2003.

122 Tal fue el caso que se enjuicia en la STSJ de Galicia de 24 de marzo de 2004 (RJCA 2004|947; Recurso 848/ 2001).

123 STSJ de Valencia de 27 de noviembre de 2001 (RJCA 2002/555; Recurso 2634/ 1997)

124 STSJ de Castilla y León, Valladolid de 17 de mayo de 2007 (JUR 2007/278212; Recurso 2082/2002)

125 RJ 2000|8616; Recurso 4305/ 1996 y RJ 200019379; Recurso 3931/ 1996

126 RJ 200019370; Recurso 3931/ 1996. 
ción de la responsabilidad patrimonial por los daños o perjuicios generados por la actividad administrativa por funcionamiento normal o anormal de los servicios puede consistir no sólo en la realización de una actividad de riesgo, sino que también puede radicar en otras circunstancias, como es, singularmente en el ámbito de la asistencia sanitaria, el carácter inadecuado de la prestación médica llevada a cabo. Esta inadecuación, como veremos que sucede en este proceso, puede producirse no sólo por la inexistencia de consentimiento informado, sino también por incumplimiento de la "lex artis ad hoc" o por defecto, insuficiencia o falta de coordinación objetiva del servicio, de donde se desprende que, en contra de lo que parece suponer la parte recurrente, la existencia de consentimiento informado no obliga al paciente a asumir cualesquiera riesgos derivados de una prestación asistencial inadecuada".

Como contrapartida debe añadirse que no cabe exigir responsabilidad por aquellos daños que, a causa de su insólito, atípico o anormal acaecimiento escapen a una común, prudente y razonable previsión de los riesgos asociados a ella. Su misma imprevisibilidad, excluyente de la culpa por su falta de prevención no sólo hace disculpable la omisión de su advertencia en la información previa debida al paciente, como ya se dejó dicho más arriba, sino que en ningún caso cabe aspirar a que se responda por ellos.

En resumidas cuentas, el consentimiento informado no libera de responsabilidad por los riesgos derivados de una actuación inadecuada, pero sí de los demás inherentes a ella e inevitables en una correcta prestación. De ahí la trascendencia de su advertencia al paciente para que pueda sopesarlos junto con otras alternativas $u$ opciones al decidir sobre el tratamiento sometido a su consideración y consentimiento, debiendo tenerse en cuenta que la falta o la insuficiencia de la información ofrecida al paciente o, lo que es igual, la omisión de un consentimiento previo y suficientemente informado acerca de los riesgos inherentes a la intervención, determina la asunción de éstos por el Centro hospitalario y, en su caso, por el facultativo, por cuanto el daño ha devenido antijurídico y el paciente no tendrá el deber jurídico de soportarlo. Así lo ha dejado afirmado la STSJ de Navarra de 6 de septiembre de $2002^{127}$ :

"la información cumplida al paciente y la obtención del debido consentimiento «informado» por él o sus representantes legales supone la asunción por éste de los riesgos y consecuencias inherentes o aso-

127 RJ 200218991; Recurso 9/ 2002. 
ciadas a la intervención, salvo las que resultase del negligente proceder del facultativo interviniente 0 al mal funcionamiento del centro 0 servicio médico en que se practica: «A sensu contrario», los daños consecuentes de una intervención que puedan ser debidos a un riesgo típico, inherente 0 asociado, aunque sean inimputables a una eventual negligencia médica en su realización, son asumidos por el facultativo si no fueron debidamente informados al paciente y éste no dio su consentimiento con conocimiento de aquéllos, como lo mantienen, igualmente, las Sentencias del Tribunal Supremo de 23 de abril de 1992 (RJ 1992/3323) y 26 de septiembre de 2000 (RJ 2000|8126) (y las posteriores del citado Tribunal de 12 de enero [RJ 2001|3], 27 de abril [R] 2001|6891] y 27 de septiembre de 2001 [RJ 2001|7130], entre otras)".

Pues bien, la Jurisprudencia ${ }^{128}$ ha dejado establecida la necesidad de que concurran los siguientes requisitos para que se produzca este desplazamiento de la asunción del riesgo desde el paciente al Centro hospitalario:

a) Que el paciente haya sufrido un daño personal cierto y probado. Sin él, la eventual omisión del consentimiento informado para una intervención médica no pasa de ser una infracción de los deberes profesionales, con posibles repercusiones en otros órdenes, pero carente de consecuencias en la esfera de la responsabilidad patrimonial.

b) Que el daño sufrido sea consecuencia de la intervención médica practicada y materialización de un riesgo típico o inherente a ella. Su exigencia no constituye sino manifestación de la necesaria relación de causalidad. El daño no sólo ha de mostrarse vinculado o ligado causalmente a la intervención, sino que ha de ser traducción de un riesgo típico o asociado a ella del que el paciente debió ser informado previamente a su realización como premisa para la obtención de su consciente y libre consentimiento.

c) Que del riesgo finalmente materializado en daño no hubiera sido el paciente informado previamente al consentimiento de la intervención. Como antes se ha dicho, es la omisión del consentimiento

128 Vid. por todas, la STSJ de Navarra de 27 de octubre de 2001 (RJ 2002|1079; Recurso 14/ 2001) y SAP de Asturias de 16 de abril de 2004 (JUR 2004|147063; Recurso 162/ 2004), que, aunque dictadas en el orden civil su doctrina es plenamente aplicable, mutatis mutandi, a la responsabilidad patrimonial de la Administración pública y, por ende, a este orden jurisdiccional. 
previa y suficientemente informado de los riesgos típicos la que determina su asunción por el médico responsable. Tratándose de un riesgo asociado a la intervención, la omisión de su advertencia es a este respecto suficiente, aunque al consentimiento hubiera precedido la información de otros posibles riesgos.

d) Que el daño constituya una incidencia de la intervención no atribuible a la negligente actuación del facultativo ni al deficiente funcionamiento del servicio. En caso contrario, será apreciable la responsabilidad, pero por culpa o negligencia en la actuación o en la organización del servicio y no por el título de imputación a que este examen se contrae. La razón no es otra que el que aquí no cabe plantear si se da o no una "relación de causalidad" (expresión que hay que entender en un sentido figurado y no en los técnicos de causalidad material, o de causalidad jurídica) entre una desinformación y el resultado dañoso producido, sino si la información recibida fue la debida para prestar el consentimiento o conformidad a la intervención, puesto que el riesgo o complicación del que no se informó, si tiene entidad suficiente hubiera bastado para que el paciente hubiera desistido de la decisión de someterse a la intervención.

e) Cuando no se haya tratado de intervención quirúrgica sino de diagnóstico, pronóstico y evolución, los daños suelen contraerse a los estados de angustia derivada de la incertidumbre y a la no adopción las medidas que lo habrían sido en caso de conocer aquellos extremos. En estos casos, si no se consigue probar que de haber recibido información la decisión adoptada por el paciente hubiese sido distinta, no podría enten derse que concurre la necesaria relación de causalidad, si bien la mayor parte de la Jurisprudencia entiende que la cuestión no debe ser ventilada por vía de la relación de causalidad en términos del binomio información-decisión, sino por la teoría del riesgo, y más concretamente por la del riesgo permitido, pues al desconocer el reclamante aquel riesgo "ex ante", no lo asumió, y el mismo quedó sólo de cargo de la parte demandada (SAP de las Islas Baleares 3 de febrero de $2003^{129}$ ). 